\title{
ESSENTIAL OIL OF Curcuma longa L. RHIZOMES CHEMICAL COMPOSITION, YIELD VARIATION AND STABILITY
}

\author{
Anabrisa Ferreira Guimarães ${ }^{\mathrm{a}}$, Ana Cláudia Andrade Vinhasa ${ }^{\mathrm{a}}$, Angélica Ferraz Gomes ${ }^{\mathrm{a}, *, \mathbb{1}}$, Luiz Humberto Souza ${ }^{\mathrm{b}}$ and \\ Patrícia Baier Krepsky ${ }^{\mathrm{a}}$ \\ anstituto Multidisciplinar em Saúde, Campus Anísio Teixeira, Universidade Federal da Bahia, 45029-094 Vitória da Conquista \\ - BA, Brasil \\ ${ }^{\mathrm{b}}$ Departamento de Fitotecnia e Zootecnia, Universidade Estadual do Sudoeste da Bahia, 45083-900 Vitória da Conquista - BA, Brasil
}

Recebido em 13/02/2020; aceito em 01/04/2020; publicado na web em 11/05/2020

\begin{abstract}
Turmeric (Curcuma longa L.) is a medicinal plant that is cultivated worldwide. This study was conducted to evaluate the variability in the percentage and the chemical composition of volatile oils from 12 turmeric samples. Rhizomes of the turmeric plant were collected from three different producers in the Brazilian like savanna (Cerrado) habitat in the state of Bahia. The chemical composition of the oils derived from the rhizomes was analysed by thin-layer chromatography and GC-MS. The average oil content was $3.97 \% \pm 0.61 \%$, varying from $3.0 \%$ to $5.16 \%$. There were differences between producers; however, all samples met the specification of the Brazilian Pharmacopoeia. Thin-layer chromatographic analysis revealed qualitative similarity in both oil and curcuminoid components among the samples. The major components identified in the oils by gas chromatography were ar-turmerone $(40.00 \% \pm 13.20 \%), \alpha$-turmerone $(10.05 \% \pm 2.90 \%)$ and curlone $(22.73 \% \pm 12.72 \%)$. Regarding stability, there was a difference between the essential oil percentages after 6 months, but the content was maintained adequate and the chromatographic profile remained similar. The vegetable raw material obtained from C. longa rhizomes produced in the western region of the state of Bahia met the quality requirement of the Brazilian Pharmacopoeia.
\end{abstract}

Keywords: chemical variability; Curcuma longa; essential oil; turmeric, stability; quality control.

\section{INTRODUCTION}

Turmeric (Curcuma longa L. Zingiberaceae), whose scientific synonyms are $C$. domestica Valeton and Amomum curcuma Jacq., ${ }^{1,2}$ is a rhizomatous herbaceous perennial plant. This species is native to Southeast Asia and extensively cultivated in the tropical and subtropical regions of the world. In India, and in several other countries, it is one of the most important spices and used as a natural yellow food pigment and in herbal medicine. ${ }^{3,4}$

In the traditional systems of Asian medicine, turmeric has been indicated for the treatment of digestive disorders, ${ }^{4,5}$ ocular infection and inflammation, diarrhea, epilepsy, wound healing, ${ }^{4}$ fever, allergies, chronic cough, bronchial asthma, jaundice, ${ }^{5}$ arthritis and other diseases. ${ }^{5,6}$

The biological activities of turmeric have been investigated in recent decades. Turmeric powder and crude extracts have been evaluated for some pharmacological activities such as hepatoprotective, ${ }^{7}$ antifungal, ${ }^{8,9}$ neuroprotective ${ }^{10,11}$ and memory improvement. ${ }^{12}$

Regarding its chemical composition, the major secondary metabolite classes include curcuminoids and sesquiterpenes. Curcumin, the primary curcuminoid, represents $3 \%-5 \%$ of turmeric. ${ }^{5,13}$ Essentially, curcumin is a commercially available mixture of curcuminoids ${ }^{4,14}$ that contains $72 \%-78 \%$ of curcumin, $12 \%-18 \%$ of demethoxycurcumin, 3\%-8\% of bisdemethoxycurcumin and organic solvent residue. ${ }^{14,15}$ Curcumin can modulate multiple pathways, which could explain the diversity in its traditional indications and pharmacological activities. ${ }^{4,16}$ Furthermore, the safety of using curcumin has been demonstrated in clinical trials even at doses $>8 \mathrm{~g}$ /day. Unfortunately, the efficacy could be questioned due to the small number of patients involved. ${ }^{17}$

\footnotetext{
*e-mail: licaferraz@yahoo.com.br
}

Low bioavailability of curcumin is another problem, and many papers are dealing with subject. Researchers have explored a few successful alternatives to increase the serum levels of curcumin, such as nanotechnology, ${ }^{17,18}$ structural analogues, ${ }^{4}$ association with sesquiterpenes derived from essential oil, ${ }^{19}$ extraction with water and enzymes from fresh rhizomes, ${ }^{15}$ encapsulate curcumin into chitosan, ${ }^{20}$ association with piperine, the major component of black pepper that increases bioavailability by $2000 \% .^{16,19}$ Besides, curcuminoids are also sensitive to light and air. ${ }^{21}$

Dried rhizomes and leaves contain approximately 5\%-6\% and $1.0 \%-1.5 \%$ of volatile oil, respectively. ${ }^{22}$ The essential oils of rhizomes are constituted primarily by sesquiterpenes, typically ar-turmerone, curlone ( $=\beta$-turmerone), ${ }^{14,23-28} \alpha$-turmerone, ${ }^{14,23-25,27,28}$ $\alpha$-curcumene (= ar-curcumene, curcumene), ${ }^{26,28} \gamma$-turmerone and $\beta$-sesquiphellandrene, ${ }^{28}$ and the monoterpenes $\beta$-pinene and paracymene. In addition, studies have reported that the essential oil has anti-inflammatory, anti-nociceptive and anti-atherosclerotic in vivo effects ${ }^{26,29}$ and antioxidant, ${ }^{26,30}$ anti-proliferative ${ }^{28}$ and anti-angiogenic in vitro activities. ${ }^{31}$ Therefore, although curcuminoids are the most investigated compounds, currently, essential oil components have demonstrated significant results in pharmacological studies.

Several factors can interfere with the chemical variation of essential oils in plants, such as temperature, humidity, luminosity, altitude, pluviometry, ultraviolet radiation, soil and nutrient conditions, seasonality, circadian cycle, method of collection, drying and part of the plant. ${ }^{32-34}$ Due to these factors, the relative composition of turmeric varies considerably with the geographical origin ${ }^{25,35}$ and different agroclimatic zones. ${ }^{33}$ The composition of turmeric essential oil also can vary with maturity. As the plant ages, the concentrations of sesquiterpenes increase, whereas those of monoterpenes decline in the rhizomes. The maximum curcumin content was found at the age of approximately 9 months after planting, after which there was a decline in the total curcumin content. ${ }^{36}$ Furthermore, the essential 
oil content positively correlates with the levels of phosphorous and potassium in the soil. ${ }^{33}$ Regarding the effect of solar radiation on the essential oil yield, $C$. longa cultivated under full sunlight treatment showed a greater yield $(3.0 \%)$ than that under treatment with shading (50\% of sunlight) $(1.90 \%){ }^{37}$

This work describes variation of the yield and chemical composition of the Brazilian $C$. longa rhizomes. The results can be important for the quality control of herbal medicine produced in the savanna (Cerrado) region of Bahia.

\section{EXPERIMENTAL}

\section{Plant material}

About one kilo of each sample of turmeric rhizomes was collected in February 2011 from three commercial producers (Producer 1 São Manoel Farm, producer 2 Manchão Branco Farm, and producer

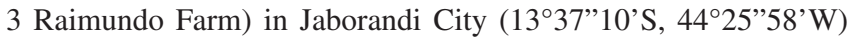
located in the Brazilian savanna (Cerrado) biome. Twelve samples were collected in the late afternoon in a period of occasional rainfall. Rhizomes were sliced, dried at $40{ }^{\circ} \mathrm{C}$ for $10 \mathrm{~h}$ and stored in paper bags. All plant materials were identified by Prof. Patrícia Baier Krepsky (Multidisciplinary Institute in Health, Federal University of Bahia, Brazil) based on the macroscopic and microscopic description presented in the Brazilian Pharmacopoeia. ${ }^{38}$ Samples have been deposited at the vegetable drug collection of the Federal University of Paraná with the numbers 122A10, 122A11, 122A12 and 122A13 (producer 1); 122A14, 122A15, 122A16 and 12A17 (producer 3) and 22A18, 122A19, 122A20 and 122A21 (producer 2). For this study, the authors obtained authorisation of access to the Brazilian System for the Management of Genetic Heritage and Associated Traditional Knowledge-SISGEN (\# AB58325).

\section{Variability in the essential oil yield}

To determine the essential oil yield, five grams of each sample with about $100 \mathrm{~mL}$ of water was subjected to the hydro-distillation method for $4 \mathrm{~h}$, using a Clevenger-type apparatus with $0.5 \mathrm{~mL}$ of xylene to solve the essential oil extracted, according to the Brazilian Pharmacopoeia procedure ${ }^{39}$ After extraction, the essentials oils were measured directly in the extraction apparatus, and the content $(\%)$ was calculated as volume $(\mathrm{mL})$ of essential oil per $100 \mathrm{~g}$ of dry plant material. These extractions were done in triplicate for each sample 1 month after the collection. All samples were triturated for no more than 1 day before analysis because of the sensitivity of the turmeric components. Average, standard deviation and relative standard deviation were calculated for the group of samples obtained from each producer as well as for the total number of collected samples. Comparisons between results obtained for each producer's samples were performed by the analysis of variance (ANOVA), applying Tukey's test to compare mean values, using the GraphPad Prism software, version 5. These results were compared with the essential oil yield recommended by the Brazilian Pharmacopoeia. ${ }^{38}$ Essential oils were stored in the freezer before conducting further chromatographic analysis.

\section{Analysis of the chemical profile of essential oil and curcumin by thin-layer chromatography}

Thin-layer chromatography (TLC) was used to verify the essential oil profile using silica gel GF254 of approximately $250-\mathrm{mm}$ thickness. ${ }^{39}$ The mobile phase was optimised previously to hexane/ ethyl acetate (9:1), and the essential oils obtained from all the 12 samples were diluted in xylene (1:1) before spotting onto the TLC plates. The plates were visualised by spraying anisaldehyde solution.

The chemical profiles were also compared qualitatively using a commercial mix of curcuminoids (curcumin, demethoxycurcumin and bisdemethoxycurcumin, Sigma Aldrich ${ }^{\circledR}$ ) as reference substances. Rhizomes were powdered and sequentially the samples were prepared with $0.5 \mathrm{~g}$ in $5 \mathrm{~mL}$ of methanol, under stirring for $30 \mathrm{~min}$, centrifuged at $2500 \mathrm{rpm}$ for 10 minutes and, filtered. Reference solution was prepared by using $5 \mathrm{mg}$ of curcuminoids (purchased from Sigma Aldrich ${ }^{\circledR}$ ) in $5 \mathrm{~mL}$ of methanol. Samples and reference solution were spotted on silica gel plates GF254. Mobile phase consisted of chloroform, ethanol, and acetic acid (95:5:0.5). After development, plate was removed, dried and, spots were visualized in UV light $(366 \mathrm{~nm}) .^{38}$

\section{Qualitative and quantitative analysis by gas chromatography coupled to a mass spectrometer}

The essential oils were analysed using a Shimadzu ${ }^{\circledR}$ QP2010 gas chromatography apparatus directly interfacing with mass (MS), equipped with a $5 \%$ diphenyl $95 \%$ dimethyl polysiloxane capillary column ( $30 \mathrm{~m} \times 0.25 \mathrm{~mm}, 0.25 \mu \mathrm{m}$ of film thickness). Helium was used as the carrier gas. The mass detector of the GC-MS equipment was operated in an electron-impact mode, with a scan range of 45-500 amu, an ionisation energy of $70 \mathrm{eV}$ and a scan rate of $0.30 \mathrm{~s}$ per scan. The temperatures of the ionisation source and the injector were maintained at $200{ }^{\circ} \mathrm{C}$ and $240{ }^{\circ} \mathrm{C}$, respectively. Other GC conditions such as the flow rate, the concentration of the sample and the separation temperature programme were optimised to provide a better separation of components in a shorter run time. Chemical constituents were identified by referring to compounds reported in the literature and by comparing their mass spectra with those of known compounds available in the database of NIST 2008 (National Institute Standard and Technology) and Flavour and Fragrances of Natural and Synthetic Compounds (FFNSC) 1.3 libraries. The identification was further supported by the calculation of their retention indices under identical experimental conditions using n-alkanes (C10-C40) series (Sigma Aldrich, USA). Retention Index (RI) was calculated for each main compound and compared to those reported in the literature data.

The relative percentage of each compound present in rhizome oil was calculated using the corresponding peak area integration, performed automatically using their own software (GCMSsolution $\left.{ }^{\circledR}\right)$. A cheque of the integration of each peak was conducted and corrected manually if necessary. The composition was reported as a relative percentage of the total peak area.

Average, standard deviation and relative standard deviation (\%) of the relative proportion areas $(\%)$ were calculated for each major peak identified and their respective retention times.

\section{Plant drug stability}

Analyses were repeated for five samples 6 months later to verify the chemical stability. A paired Student's $t$-test was used to assess whether the samples had stability in terms of the essential oil yield and the relative area of the major oil components by gas chromatography. Besides, the effect of the Clevenger extraction on the volatile compounds were evaluated analysing the composition of these volatiles after extraction of $1 \mathrm{~g}$ of three samples with $20 \mathrm{~mL}$ hexane. The extract was injected in the GC-MS employing the same conditions.

\section{RESULTS AND DISCUSSION}

\section{Variability in the essential oil yield}

C. longa populations collected from three different producers 
were investigated for their essential oil yield and chemical composition. Extractions of essential oils from each sample were carried out in triplicate, and their average yield of oils obtained from all samples was $3.97 \% \pm 0.61 \%$ and the variation among the producers was $3.0 \%-5.16 \%$ (relative standard deviation $=15.3 \%$ ) in the dry material. The average yield for each producer was as follows: producer $1,3.83 \% \pm 0.17 \%(4.3 \%)$; producer $2,4.58 \% \pm 0.58 \%(14.7 \%)$ and producer $3,3.48 \% \pm 0.59 \%(16.9 \%)$. Comparisons between producers performed by ANOVA showed significant differences. A significant difference $(\mathrm{p}=0.05)$ was found only between producers 2 and 3 (Tukey's test). Despite the significant variation in oil yields among the producers, all the analysed samples had an oil yield within the values specified by the Brazilian Pharmacopoeia. Therefore, the turmeric samples grown in the Brazilian savanna region of Bahia state are suitable for use in herbal medicine preparations, considering that the essential oil content should be at least $2.5 \%$ as recommended by the Brazilian Pharmacopoeia. ${ }^{38}$

According to earlier studies, C. longa essential oil yield in dry rhizomes varied from $1.5 \%$ to $5.0 \% .{ }^{14}$ Similarly, other researchers found $2.9 \%^{27}$ and $3.8 \%$ of essential oil yields. Similar variations ranging from $2.1 \%{ }^{41}$ to $4.4 \%{ }^{42}$ were found in Brazil. Therefore, C. longa cultivated in the Brazilian savanna could produce highquality turmeric in terms of the essential oil yield.

In India, some researchers have reported essential oil yields between $0.61 \%$ and $1.45 \%$ in the fresh rhizomes of 27 accessions from the northern part of the country ${ }^{25}$ and between $0.37 \%$ and $0.8 \%$ on different agroclimatic zones. ${ }^{33}$

\section{Analysis of the chemical profile of essential oil and curcumin by TLC}

TLC analysis of the essential oil samples resulted in in at least four main violet spots. The chromatographic profiles demonstrated significant similarity among all samples. Subsequent analysis of the methanol extract revealed the presence of three major curcuminoids, which is consistent with that described in the Brazilian Pharmacopoeia.

\section{Qualitative and quantitative analysis by gas chromatography coupled to a mass spectrometer}

After testing and evaluation of several different conditions of chromatographic parameters (concentration of the sample, inlet mode, flow rate and separation temperature programme), the best parameters were as follows: a flow rate of $1.5 \mathrm{~mL} \mathrm{~min}^{-1}$, a concentration of $2.5 \%$ of the sample in dichloromethane and a temperature programme column as described in Table 1. Using this developed method, it was possible to separate all the substances satisfactorily within $20 \mathrm{~min}$ as shown in Figure 1. This method proved to be more advantageous than other methods described in the literature ${ }^{40,42,43}$ because of the shorter analysis time.

Table 1. Temperature program for GC analysis of essential oils

\begin{tabular}{ccc}
\hline Rate $\left({ }^{\circ} \mathrm{C} \mathrm{min}^{-1}\right)$ & Final temperature $\left({ }^{\circ} \mathrm{C}\right)$ & Hold time $(\mathrm{min})$ \\
\hline- & 80.0 & 2 \\
30 & 160.0 & 1 \\
1 & 160.5 & 1 \\
1 & 160.8 & 1 \\
1 & 160.9 & 1 \\
1 & 161.0 & 2 \\
1 & 161.2 & 1 \\
1 & 161.5 & 1 \\
1 & 162.0 & 1 \\
20 & 180.0 & 0 \\
30 & 240.0 & 2 \\
\hline
\end{tabular}

Seven compounds were identified in the essential oil by comparing the RI (literature and RI taken from NIST 2008 library) and mass spectra of each peak with the NIST and 1.3 FFNSC libraries (similarity $>90 \%$ ). The major compounds identified were ar-turmerone (5), turmerone ( $\alpha$-turmerone) (6) and curlone ( $\beta$-turmerone) (7). Some minor components were also identified, including $\alpha$-phellandrene (1), $\alpha$-curcumene (ar-curcumene, curcumene) (2), $\beta$-bisabolene and (3) $\beta$-sesquiphellandrene (4) (Table 2).

Analyses of the samples were performed by peak area normalisation. Table 2 shows the average, standard deviation and the relative standard deviation (RSD\%) values of the relative proportion area \% (RPA).

Table 3 shows the results of the comparison between the relative percentages of $C$. longa essential oil obtained in this study and those reported in the literature using MS. This comparison revealed that the major compounds reported in the literature were similar to those observed in the present study.

In order to verify if there was no conversion of turmerol in

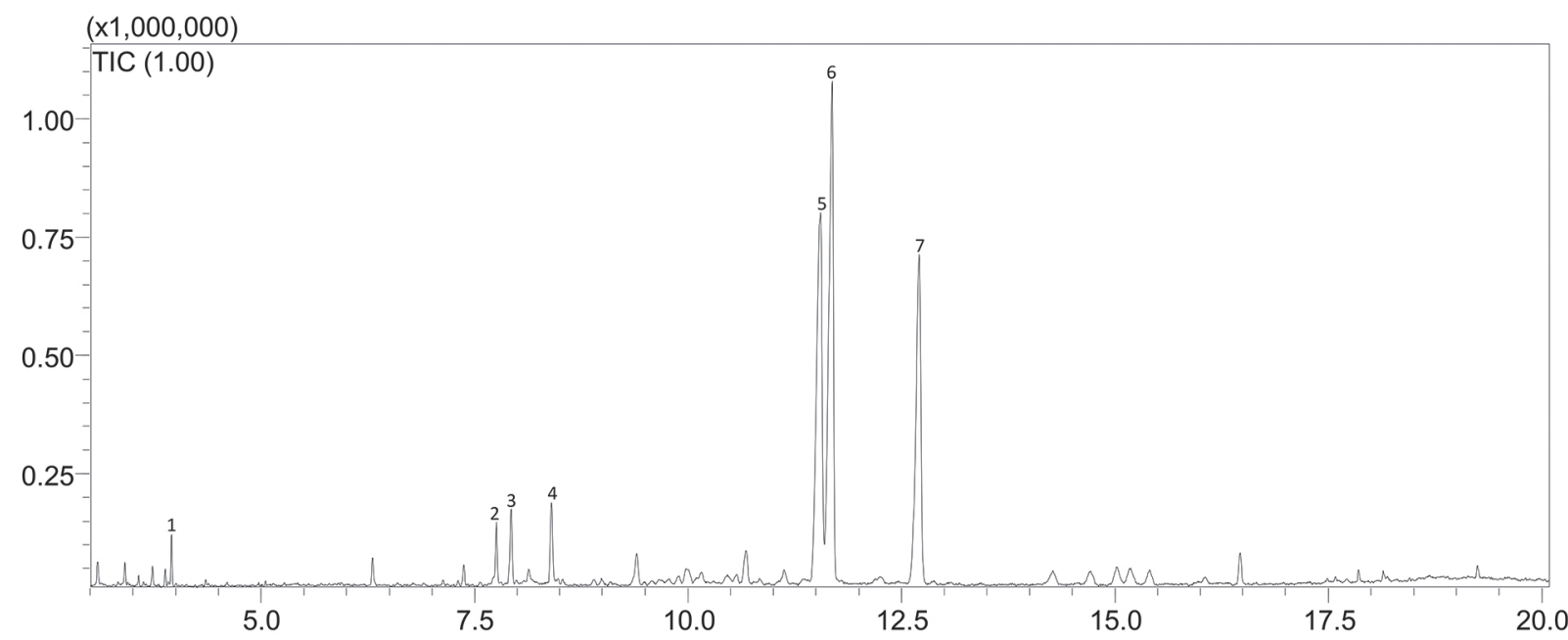

Figure 1. Essential oil GC-MS chromatogram of C. longa rhizomes 
Table 2. Relative percentage of $C$. longa essential oil main components and comparison between quantitative analysis performed by GC-MS

\begin{tabular}{|c|c|c|c|c|c|c|c|}
\hline \multirow[t]{2}{*}{ Compound } & \multirow[t]{2}{*}{$\mathrm{RT}(\min )$} & \multirow[t]{2}{*}{$\mathrm{RI}^{\mathrm{a}}$} & \multirow[t]{2}{*}{$\mathrm{RI}^{\mathrm{b}}$} & \multicolumn{4}{|c|}{$\begin{array}{c}\text { Relative proportion area (\%) } \\
\text { Average } \pm \text { SD }(\text { RSD \%) }\end{array}$} \\
\hline & & & & Producer 1 & Producer 2 & Producer 3 & Total \\
\hline$\alpha$-phellandrene (1) & 3.73 & 1015 & $1010^{44}$ & $0.38 \pm 0.07(17.52)$ & - & $0.30 \pm 0.08(26.46)$ & $0.35 \pm 0.07(21.21)$ \\
\hline$\alpha$-curcumene (2) & 7.76 & 1453 & $1471^{45}$ & $1.60 \pm 0.13(8.24)$ & $2.10 \pm 0.41(19.61)$ & $1.62 \pm 0.29(17.83)$ & $1.77 \pm 0.36(20.37)$ \\
\hline$\beta$-bisabolene (3) & 8.14 & 1456 & $1451 *$ & $0.41 \pm 0.13(31.89)$ & $0.49 \pm 0.05(10.23)$ & $0.44 \pm 0.09(20.22)$ & $0.45 \pm 0.09(19.39)$ \\
\hline$\beta$-sesquiphellandrene (4) & 8.41 & 1464 & $1446^{*}$ & $2.45 \pm 0.26(10.78)$ & $2.32 \pm 0.55(23.76)$ & $2.53 \pm 0.31(12.17)$ & $2.44 \pm 0.37(15.16)$ \\
\hline Ar-turmerone (5) & 11.56 & 1634 & $1631^{44}$ & $28.87 \pm 3.54(12.26)$ & $38.27 \pm 6.99(18.25)$ & $26.79 \pm 4.82(18.00)$ & $31.31 \pm 7.09(22.65)$ \\
\hline Turmerone (6) & 11.70 & 1636 & $1631^{44}$ & $26.72 \pm 3.78(14.14)$ & $15.43 \pm 8.37(54.23)$ & $25.07 \pm 4.71(18.81)$ & $22.41 \pm 7.49(33.42)$ \\
\hline Curlone (7) & 12.72 & 1652 & $1647^{44}$ & $21.71 \pm 1.48(6.83)$ & $20.20 \pm 3.30(16.32)$ & $20.27 \pm 2.70(13.31)$ & $20.73 \pm 2.47(11.89)$ \\
\hline
\end{tabular}

RT - Retention time. SD - Standard deviation. RSD - Relative standard deviation. RI ${ }^{\mathrm{a}}$ - Retention indices on Rtx ${ }^{\circledR}-5 \mathrm{MS}$ (5\% diphenyl/95\% dimethyl polysiloxane) capillary, experimentally determined using homologous series of C-10-C40 $\mathrm{n}$ alkanes. $\mathrm{RI}^{\mathrm{b}}$ - Literature retention indices. *NIST library (2008) retention indices.

Table 3. Comparison between relative percentages from GC-MS with literature

\begin{tabular}{|c|c|c|c|c|c|c|c|}
\hline \multirow{2}{*}{ Reference } & \multicolumn{7}{|c|}{ Compound } \\
\hline & (1) & (2) & (3) & (4) & (5) & (6) & $(7)$ \\
\hline Current study & $0.35 \pm 0.07$ & $1.77 \pm 0.36$ & $0.45 \pm 0.09$ & $2.4 \pm 0.37$ & $31.31 \pm 7.09$ & $22.41 \pm 7.49$ & $20.73 \pm 2.47$ \\
\hline Angel et al., $2014^{23}$ & - & - & - & 0.8 & 49.8 & 9.1 & 7.9 \\
\hline Asghari et al., $2009^{46}$ & 2.2 & - & 0.4 & 1.3 & 68.9 & 20.9 & - \\
\hline Avanço et al., $2017^{47}$ & 6.5 & 1.0 & 0.3 & 1.4 & 12.9 & 42.6 & 16.0 \\
\hline Garg et al., $1999 * 25$ & - & 1.9 & - & - & 25.4 & 11.9 & 8.3 \\
\hline Leela et al., $2002^{40}$ & - & 6.3 & - & 2.6 & 31.1 & 10.0 & 10.6 \\
\hline Liju et al., $2011^{26}$ & - & 6.1 & - & - & 61.79 & - & 12.48 \\
\hline Sahoo et al., 201948 & $5.5-5.7$ & - & - & - & $39.5-45.5$ & - & $9.8-11.7$ \\
\hline Sandeep et al., 2016**33 & $0-5.38$ & $0-3.93$ & $0-3.13$ & $0-4.17$ & - & $40.08-56.42$ & $12.55-25.95$ \\
\hline Singh et al., $2010^{27}$ & trace & 6.6 & 4.1 & 4.2 & 21.4 & 0.6 & 4.3 \\
\hline Zhang et al., 2017***43 & - & - & - & $10.26-14.88$ & $22.20-42.85$ & - & $13.28-14.61$ \\
\hline
\end{tabular}

*Average from 27 accessions. $* * 9$ accessions. $* * * 20$ accessions.

turmerone, extraction with hexane solvent was carried out by maceration at room temperature. GC-MS analysis of this extract showed the peak of ar-turmerone and curlone but not of turmerone. These results indicate the possibility of the conversion of turmerol to turmerone may have occurred during the hydrodistillation processes. However, previous studies in literature do not mention this type of conversion.

\section{Plant drug stability}

As mentioned earlier, the average volatile oil yield was 3.97\%. The repeated analysis performed after 6 months showed an average yield of $3.50 \%$ with variations between $2.98 \%$ and $3.94 \%$ (RSD\%: 10.42). Although there was a significant reduction ( $\mathrm{p}=0.06, t$-test $)$ in the volatile oil yield, the remaining were within the standards recommended by the Brazilian Pharmacopoeia. The chromatographic profile analysed by TLC remained similar. Concerning about the analysis by GC-MS, from a qualitative point of view, the only difference was the absence of $\alpha$-phellandrene. However, the percentage of this compound was too small since the first testing of each sample (average $0.35 \%$ ). On the basis of all these results, it can be concluded that the plant drug exhibited satisfactory stability after the 6-month storage period, despite the small decrease in the essential oil content

\section{CONCLUSIONS}

The yield $(3.97 \% \pm 0.61 \%)$ and the chemical composition of the essential oils obtained from the rhizomes of $C$. longa were similar to those of high-yield accessions described in the literature. Therefore, based on the parameters analysed in this study, the samples found in the Brazilian savanna region fulfilled the quality requirements. Moreover, the primary advantage of the current method of GC-MS analysis was its shorter analysis time, i.e. only $20 \mathrm{~min}$. Regarding stability, the content was maintained adequate and the chromatographic profile remained similar even 6 months after harvest.

\section{ACKNOWLEDGEMENTS}

The authors are grateful for Dr. Juliano Geraldo Amaral for editing the pictures and FAPESB (Fundação de Amparo à Pesquisa do Estado da Bahia) for the financial support.

\section{REFERENCES}

1. Leong-Škorničková, J.; Šída, O.; Wijesundara, S.; Marhold, K.; Bot. J. Linn. Soc. 2008, 157, 37.

2. Missouri Botanical Garden, Tropicos 2018, Available at: https://www. tropicos.org/nameSearch?name=Curcuma\%20longa, accessed at May 2020 . 
3. Gupta, A. K.; Mishra, R.; Lal, R. K.; Ind. Crops Prod. 2015, 77, 708.

4. Noorafshan, A.; Ashkani-Esfahani, S.; Curr. Pharm. Des. 2013, 19, 2032.

5. Sarker, S. D.; Nahar, F. In Turmeric: The Genus Curcuma, Ravisdran, P. N.; Babu, K. N.; Sivaraman, K., eds., CRC Press: Boca Raton, New York, London, 2007, cap. 9.

6. Funk, J. L.; Oyarzo, J. N.; Frye, J. B.; Chen, G.; Lantz, R. C.; Jolad, S. D.; Sólyom, A. M.; Timmermann, B. N.; J. Nat. Prod. 2006, 69, 351.

7. Hossen, M. S.; Tanvir, E. M.; Prince, M. B.; Paul, S.; Saha, M.; Ali, M. Y.; Gan, S. H.; Khalil, M. I.; Karim, N.; Pharm. Biol. 2017, 55, 1937.

8. Neelofar, K.; Shreaz, S.; Rimple, B.; Muralidhar, S.; Nikhat, M.; Khan, L. A.; Can. J. Microbiol. 2011, 57, 204.

9. Sharma, M.; Manoharlal, R.; Negi, A. S.; Prasad, R.; FEMS Yeast Res. 2010, 10, 570 .

10. Kadri, Y.; Nciri, R.; Brahmi, N.; Saidi, S.; Harrath, A. H.; Alwasel, S.; Aldahmash, W.; El Feki, A.; Allagui, M. S.; Environ. Sci. Pollut. Res. 2018, 25, 19555.

11. Yuliani, S.; Mustofa; Partadiredja, G.; Nutr. Neurosci. 2018, 22, 797.

12. Serafini, M. M.; Catanzaro, M.; Rosini, M.; Racchi, M.; Lanni, C.; Pharmacol. Res. 2017, 124, 146.

13. Joe, B.; Vijaykumar, M.; Lokesh, B. R.; Crit. Rev. Food Sci. Nutr. 2004, 44, 97.

14. Li, S.; Yuan, W.; Deng, G.; Wang, P.; Yang, P.; Aggarwal, B. B.; Pharm. Crops 2011, 2, 28.

15. Krishnakumar, I. M.; Kumar, D.; Ninan, E.; Kuttan, R.; Maliakel, B.; J. Funct. Foods 2015, 17, 55.

16. Gupta, S. C.; Patchva, S.; Koh, W.; Aggarwal, B. B.; Clin. Exp. Pharmacol. Physiol. 2012, 39, 283.

17. Schaffer, M.; Schaffer, P. M.; Bar-Sela, G.; Curr. Opin. Clin. Nutr. Metab. Care 2015, 18, 605.

18. Lu, P. S.; Inbaraj, B. S.; Chen, B. H.; J. Sci. Food Agric. 2018, 98, 51.

19. Antony, B.; Merina, B.; Iyer, V.; Judy, N.; Lennertz, K.; Joyal, S.; Indian J. Pharm. Sci. 2008, 70, 445.

20. Parize, A. L.; Stulzer, H. K.; Laranjeira, M. C. M.; Brighente, I. M. da C.; de Souza, T. C. R.; Quim. Nova 2012, 35, 1127.

21. Souza, C.; J. Food Process. Preserv. 1997, 21, 353.

22. Chempakam, B.; Parthasarathy, V. A. In Chemistry of Spices, Parthasarathy, V. A., Chempakam, B., Zachariah, T. J., eds.; CABI: Cambridge, 2008, cap. 6.

23. Angel, G. R.; Menon, N.; Vimala, B.; Nambisan, B.; Ind. Crops Prod. 2014, 60, 233.

24. Balakrishnan, K. V. In Turmeric: The Genus Curcuma, Ravisdran, P. N.; Babu, K. N.; Sivaraman, K., eds., CRC Press: Boca Raton, New York, London, 2007, cap. 8.

25. Garg, S. N.; Bansal, R. P.; Gupta, M. M.; Kumar, S.; Flavour Fragrance J. 1999, 14, 315 .
26. Liju, V. B.; Jeena, K.; Kuttan, R.; Indian J. Pharmacol. 2011, 43, 526.

27. Singh, G.; Kapoor, I. P. S.; Singh, P.; de Heluani, C. S.; de Lampasona, M. P.; Catalan, C. A. N.; Food Chem. Toxicol. 2010, 48, 1026.

28. Tyagi, A. K.; Prasad, S.; Yuan, W.; Li, S.; Aggarwal, B. B.; Invest. New Drugs 2015, 33, 1175.

29. Singh, V.; Rana, M.; Jain, M.; Singh, N.; Naqvi, A.; Malasoni, R.; Dwivedi, A. K.; Dikshit, M.; Barthwal, M. K.; Br. J. Nutr. 2015, 113, 100.

30. Sueth-Santiago, V.; Mendes-Silva, G. P.; Decoté-Ricardo, D.; de Lima, M. E. F.; Quim. Nova 2015, 38, 538.

31. Yue, G. G. L.; Kwok, H. F.; Lee, J. K. M.; Jiang, L.; Chan, K. M.; Cheng, L.; Wong, E. C. W.; Leung, P. C.; Fung, K. P.; Lau, C. B. S.; J. Funct. Foods 2015, 15, 243.

32. Gobbo-Neto, L.; Lopes, N. P.; Quim. Nova 2007, 30, 374.

33. Sandeep, I. S.; Kuanar, A.; Akbar, A.; Kar, B.; Das, S.; Mishra, A.; Sial, P.; Naik, P. K.; Nayak, S.; Mohanty, S.; Ind. Crops Prod. 2016, 85, 229.

34. Gomes, A. F.; Almeida, M. P.; Leite, M. F.; Schwaiger, S.; Stuppner, H.; Halabalaki, M.; Amaral, J. G.; David, J. M.; Food Chem. 2019, 273, 186.

35. Gomes, A. F.; Ganzera, M.; Schwaiger, S.; Stuppner, H.; Halabalaki, M.; Almeida, M. P.; Leite, M. F.; Amaral, J. G.; David, J. M.; Microchem. J. 2018, 138, 494.

36. Cooray, N.; Jansz, E.; Ranatunga, J.; Wimalasena, S.; J. Natl. Sci. Counc. Sri Lanka 1988, 16, 39.

37. Bezerra, A. N.; de Oliveira, R. B.; da Silva, R.; Maia, J. G. S.; Mourão, R. H. V.; Rev. Fitos 2016, 10, 283.

38. Farmacopeia Brasileira, 5a. ed, ANVISA: Brasília, 2010, Vol. 2.

39. Farmacopeia Brasileira, 5a. ed, ANVISA: Brasília, 2010, Vol. 1.

40. Leela, N.; Aldo, T.; Shafi, P. M.; Acta Pharm. 2002, 52, 137.

41. Braga, M. E. M.; Leal, P. F.; Carvalho, J. E.; Meireles, M. A.; J. Agric. Food Chem. 2003, 51, 6604.

42. Péret-Almeida, L.; Naghetini, C. C.; Nunan, E. A.; Junqueira, R. G.; Glória, M. B. A.; Cienc. Agrotecnol. 2008, 32, 875.

43. Zhang, L.; Yang, Z.; Chen, F.; Su, P.; Chen, D.; Pan, W.; Fang, Y.; Dong, C.; Zheng, X.; Du, Z.; Ind. Crops Prod. 2017, 109, 60.

44. Gardini, F.; Belletti, N.; Ndagijimana, M.; Guerzoni, M. E.; Zollo, P. H. A.; Micci, C.; Lanciotti, R.; Sylvain, L.; Kamdem, S.; Afr. J. Microbiol. Res. 2009, 3, 264.

45. Babushok, V. I.; Linstrom, P. J.; Zenkevich, I. G.; J. Phys. Chem. Ref. Data 2011, 40,1.

46. Asghari, G.; Mostajeran, A.; Shebli, M.; Res. Pharm. Sci. 2009, 4, 55.

47. Avanço, G. B.; Ferreira, F. D.; Bonfim, N. S.; dos Santos, P. A. de S. R.; Peralta, R. M.; Brugnari, T.; Mallmann, C. A.; de Abreu Filho, B. A.; Mikcha, J. M. G.; Machinski, M.; Food Control 2017, 73, 806.

48. Sahoo, A.; Kar, B.; Jena, S.; Dash, B.; Ray, A.; Sahoo, S.; Nayak, S.; J. Essent. Oil-Bear. Plants 2019, 22, 239. 